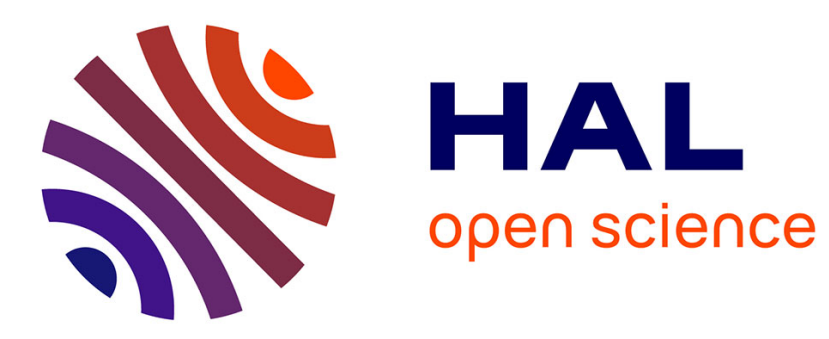

\title{
Interaction of Cerium Species with Alumina-Filmed Surfaces
}

\author{
J. Wan, G. Thompson, K. Lu, C. Smith
}

\section{To cite this version:}

J. Wan, G. Thompson, K. Lu, C. Smith. Interaction of Cerium Species with Alumina-Filmed Surfaces. Journal de Physique IV Proceedings, 1997, 7 (C2), pp.C2-1181-C2-1182. 10.1051/jp4:19972183 jpa00255252

\section{HAL Id: jpa-00255252 https://hal.science/jpa-00255252}

Submitted on 1 Jan 1997

HAL is a multi-disciplinary open access archive for the deposit and dissemination of scientific research documents, whether they are published or not. The documents may come from teaching and research institutions in France or abroad, or from public or private research centers.
L'archive ouverte pluridisciplinaire HAL, est destinée au dépôt et à la diffusion de documents scientifiques de niveau recherche, publiés ou non, émanant des établissements d'enseignement et de recherche français ou étrangers, des laboratoires publics ou privés. 


\title{
Interaction of Cerium Species with Alumina-Filmed Surfaces
}

\author{
J. Wan, G.E. Thompson, K.Q. Lu* and C.J.E. Smith** \\ Corrosion and Protection Center, UMIST, Manchester M60 1QD, UK \\ * Institute of Physics, Chinese Academy of Sciences, Beijing, 100080, China \\ ** Defence Research Agency, Farnborough, Hants, GU14 6TD, UK
}

\begin{abstract}
Cerium compounds have been shown to improve the corrosion resistance of aluminium alloys in aggressive media; the mechanisms of inhibition are the subject of debate, with the valence state of the $\mathrm{Ce}$ species on the aluminium surface reported to be +3 and +4 , depending on immersion time and solution oxygen content. In order to provide greater understanding, the effect of cerium species on the corrosion of superpure aluminium, with minimal second phase material, has been examined here, using XANES and analytical TEM of ultramicrotomed sections. It is revealed that cerous species are largely present, initially above a hydrated alumina film and are converted slowly to the more stable $\mathrm{Ce}^{4+}$ state in the aerated environment. Such data allow the mechanism of film growth to be elucidated and consideration of the improvement in the corrosion behaviour of the superpure aluminium substrate supporting the film. The latter results from the blocking effect of the film over the macroscopic aluminium surface, limiting the anodic process of metal loss, and reduction of the cathodic kinetics through cerium-containing deposits at preferred sites.
\end{abstract}

\section{INTRODUCTION}

Treatment of aluminium in $\mathrm{CeCl}_{3}$ solution is claimed to provide good corrosion protection to aluminium alloy substrates. However, apart from SEM observation of the treated surface topography, little been reported on the detailed film characterization; further, mechanisms of coating formation and protection are not well established. In the present work, characterization of the film formed on relatively pure aluminium, including coating morphology in both plan and section, and the valence states of incorporated cerium species, have been determined; with assessment of the electrochemical behaviour of the treated specimens, insight into the mechanisms of film formation and resultant corrosion resistance is given.

\section{EXPERIMENTAL}

Coatings, formed on electropolished $99.99 \%$ aluminium sheets, by immersion in $10,000 \mathrm{ppm} \mathrm{CeCl}_{3}$ solution for 7 and 14 days, and those subjected to further immersion in $0.5 \mathrm{M} \mathrm{NaCl}$ for 7 and 14 days were examined by transmission electron microscopy (TEM) of ultramicrotomed sections, and by XANES for the valence states of incorporated cerium species. Ce $\mathrm{L}_{\mathrm{II}}$ edge XANES was undertaken at beamline $7 \mathrm{C}$ at the Photon Factory, Japan, in the fluorescence mode, ex-situ in air, under conditions similar to those described previously[1]. Finally, the electrochemical behaviour of the variously treated specimens was assessed by the anodic and cathodic polarization in $0.5 \mathrm{M} \mathrm{NaCl}$ solution.

\section{RESULTS AND INTERPRETATION}

$\mathrm{Ce} \mathrm{L}_{1 \mathrm{II}}$-edge standard spectra were determined for the model compounds $\mathrm{CeCl}_{3}, 7 \mathrm{H} 2 \mathrm{O}$ and $\mathrm{CeO}_{2}$, providing references for $\mathrm{Ce}^{3+}$ and $\mathrm{Ce}^{4+}$ species respectively (Fig.1). From the Ce $\mathrm{L}_{\mathrm{II}}$-edge XANES spectra of the standards, it is evident that for Ce $\mathrm{C}^{3+}$ species the absorption edge has a sharp whiteline while, for $\mathrm{Ce}^{4+}$, the whiteline splits into two peaks, providing information for recognition of and discrimination between cerium valence states. Figure 1 also shows Ce $\mathrm{L}_{\mathrm{III}}$-edge spectra obtained from mixtures of the standard compounds, $\mathrm{CeCl}_{3} .7 \mathrm{H} 2 \mathrm{O}$ and $\mathrm{CeO}_{2}$, in different proportions. With increasing $\mathrm{CeO}_{2}$ content, the height of the second peak increases proportionally; therefore, by direct observation of the edge shape of the spectra, information on the constitution of the film may be obtained.

Curves a and $c$ in Figure 2 are the spectra for the specimens which were immersed for 7 and 14 days in 10,000 ppm $\mathrm{CeCl}_{3}$ solution respectively. TEM of the corresponding specimens, shown in the insets (2a) and (2b) of Fig.2, reveals the coatings developed after similar immersion periods. 7 days immersion results in a film comprised of two layers, with an outer cerium containing layer. The film becomes more uniform after 14 days of immersion, although the thickness remains unchanged. It is clear that, compared with the standard spectra, after 7 days immersion, the Ce species are present mainly in the $\mathrm{Ce}^{3+}$ state, with relatively little $\mathrm{Ce}^{4+}$ detected. 14 days immersion resulted in an increased presence of $\mathrm{Ce}^{4+}$ species, indicated from the second peak in the spectrum. The edge heights for both specimens are similar, suggesting that there is no 
further increase in the quantity of cerium species associated with the coating and some $\mathrm{Ce}^{3+}$ species convert to $\mathrm{Ce}^{4+}$ during protracted immersion in the $\mathrm{CeCl}_{3}$ solution.

After immersion of specimens previously treated in $\mathrm{CeCl}_{3}$ solution in $0.5 \mathrm{M} \mathrm{NaCl}$ for 7 and 14 days, the absorption edge heights decrease dramatically, revealing loss of cerium species. For specimens immersed for 7 and 14 days in the coating solution, the cerium signals decrease by about $60 \%$ and $90 \%$ after 7 and 14 days exposure to $\mathrm{NaCl}$ solution respectively. The residual cerium species associated with the coatings are in $\mathrm{Ce}^{4+}$ valence states only, revealed by curves $b$ and $d$ in Fig. 2 .

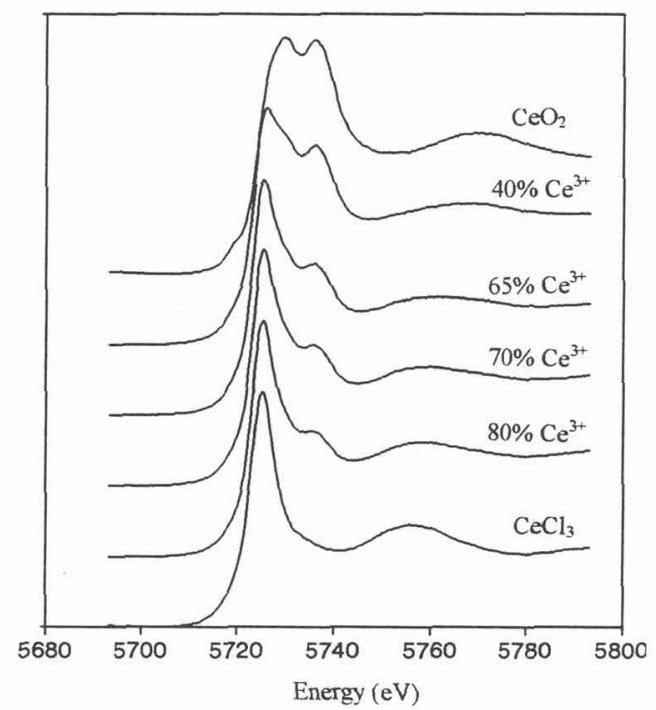

Figure 1: Ce L lil edge XANES spectra of standard compounds.

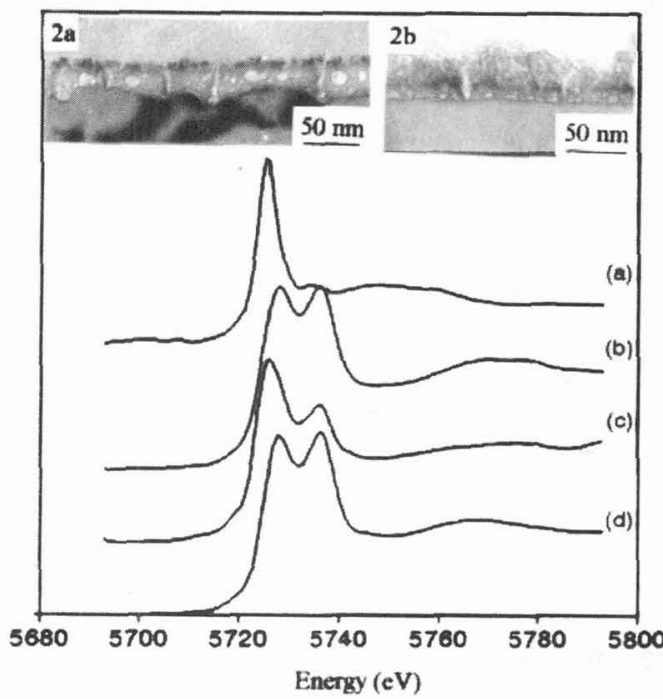

Figure 2: Ce $\mathrm{L}_{\text {III }}$ edge XANES spectra of the coated Al.

It is suggested that during immersion in the $\mathrm{CeCl}_{3}$ solution, the slightly acidic solution thins the air-formed alumina film, which enables the anodic reaction of aluminium oxidation and cathodic reaction of oxygen reduction to occur. Cathodic reactions can proceed at second phase particles and grain boundaries, or other impurity segregate sites, or over sufficiently thin residual alumina by electron tunnelling. Both chemical dissolution of alumina and cathodic reduction generate alkaline conditions which promote precipitation of cerium hydroxide, $\mathrm{Ce}(\mathrm{OH})_{3}$. The presence of $\mathrm{Ce}^{4+}$ species, likely in the form of $\mathrm{CeO}_{2}$, which increases with prolonged immersion, results from oxidation of the existing $\mathrm{Ce}^{3+}$ ions by dissolved oxygen in the solution, and/or by $\mathrm{H}_{2} \mathrm{O}_{2}[2]$, an intermediate during the cathodic reduction of oxygen. Results obtained from XANES analysis of coatings show the tendency for conversion of $\mathrm{Ce}^{3+}$ into $\mathrm{Ce}^{4+}$ species with time of immersion and, after immersion of coatings in $\mathrm{NaCl}$ solution for a period of time, only $\mathrm{Ce}^{4+}$ species remain in the coating, indicating their instability.

The immersion process takes weeks or months to develop a sufficiently protective coating on the aluminium substrate[3] and the present work shows for superpure aluminium that improved pitting potentials are reached only after 14 days immersion. This likely results from i) the relatively slow reaction of alumina with the solution at room temperature and ii) the slow conversion of the incorporated $\mathrm{Ce}^{3+}$ species to $\mathrm{Ce}^{4+}$ species in the outer film regions.

Both anodic and cathodic polarization behaviour of the coated aluminium in $\mathrm{NaCl}$ solution reveal that protracted immersion treatment provides improved properties to the aluminium substrate, e.g. higher pitting potential and lower cathodic current density values, which may result from the more uniform coating with increased $\mathrm{Ce}^{4+}$ levels acting as a barrier above the aluminium substrate. TEM observation of the coating shows a more uniform and less porous coating with increased immersion time. Further, the outer cerium containing coating probably limits loss of aluminium to solution. On the other hand, precipitation of cerium species at active cathodic sites is expected to reduce the cathodic reduction reaction, i.e. oxygen reduction, which reduces the corrosion rate.

In summary, the corrosion inhibition of aluminium resulting from cerium immersion treatment is exhibited in two ways; i) the cerium-containing film provides a protective barrier over the substrates and ii) impedes the cathodic half reactions of the corrosion process, by blocking the cathodic sites, and limiting reactant transport, resulting in corrosion inhibition.

References

[1] J.Wan, G.E.Thompson, K.Lu, C.J.E.Smith, Physica B, $208 \& 209$ (1995) $511-512$.

[2] B.R.W.Hinton and L.Wilson, Corros. Sci., 29, 967(1989).

[3] D.R.Amott, B.R.W.Hinton and N.E.Ryan, Corrosion, 45, 12(1989). 